\title{
STUDY PERENCANAAN GEOMETRIK, PERKERASAN JALAN DAN PERENCANAAN ANGGARAN BIAYA PADA JALAN RAYA KALIDAWIR - Ds. NGUBALAN Kec. KALIDAWIR
}

\author{
Edy Gardjito,ST.MT.
}

\author{
Staf Pengajar Program Studi Teknik Sipil Fakultas Teknik Universitas Kadiri \\ e-mail : edygardjito@unik-kediri.ac.id
}

\begin{abstract}
ABSTRACK
So, here the author took the initiative to plane the road using flexible pavement. The hope for future, so it can be use as well as possible for the local Villagers. Even There included connecting roads between several villages.The method use in this planning is a method that is often used lag other planners, namely : Book Of Directorate General of Bina marga, 1970. Regulation Of Road Geometric Planning Directorate General Of Bina Marga, 1997. Procedures for planning geometric the inter city roads, The Center For Research and Development Jakarta, and use of others literature. The conclusion that can be get planning for this is, this way it is \pm 3.200 meter with width across 7 meter. Is available is 2 aligment horizontal PI 1 With radisius 200 meter as big as 34'33,5'5,82'. PI 2 radisius plan

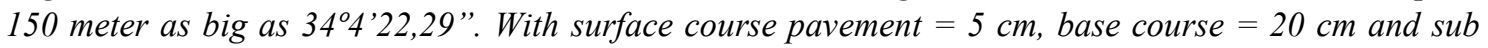
base course $=15 \mathrm{~cm}$.
\end{abstract}

Keyword : Road Geometric Planning, Flexible Pavement and RAB

\section{PENDAHULUAN}

\section{Latar Belakang}

Jalan adalah prasarana transportasi darat yang meliputi segala bagian jalan, termasuk didalamnya ada bangunan pelengkap dan perlengkapan lainnya yang diperuntukkan bagi lalu lintas tersebut, yang berada pada permukaan tanah, di atas permukaan tanah, di bawah permukaan tanah dan/atau air, serta di atas permukaan air, kecualijalan kabel, jalan lori, danjalan kereta api. Pada jalan Kalidawir - Desa Ngubalan ini menghubungkan dua desa yang berada di daerah pegunungan bagian selatan Tulungagung.

\section{Identifikasi Masalah}

a. Perencanaan Geometrik Jalan

Perencanaan geometrik jalan merupakan sebuah bagian dari perencanaan jalan yang tertitik beratkan pada alinyemen horizontal dan alinyemen vertikal, sehingga dapat memenuhi fungsi dasar dari jalan yang mampu memberikan kenyamanan yang optimal pada arus lalu lintas dan sebagai akses ke rumah - rumah.

b. Perencanaan Tebal Perkerasan Lentur

Dalam pembahasan kali ini memuat tentang perencanaan jalan baru yang 
menghubungkan dua Desa di daerah Tulungagung. Sedangkan penentuan tebal perkerasan yang direncanakannya sesuai dengan Petunjuk Perencanaan Tebal Perkerasan Lentur Jalan Raya. Dengan Metode Analisis Komponen Dinas Pekerjaan Umum Bina Marga.

c. Rencana Anggaran Biaya

Perhitungan rencana anggaran biaya biasanya meliputi :

1) Volume Pekerjaan

2) Analisa Harga Satuan Pekerjaan, bahan dan peralatan

3) Alokasi Waktu Penyelesaian masing-masing item pekerjaan

\section{Rumusan Masalah.}

1. Bagaimana alinyemen horizontal dan alinyemen vertikal?

2. Berapa tebal perkerasan lenturnya?

3. Berapa Rencana Anggaran Biaya dan Time Schedulnya?

\section{Batasan Masalah}

Untuk menghindari melebarnya suatu permasalahan, penulis membuat batasan- batasan permasalahan yang berhubungan dengan penulisan ini. Adapun batasan- batasan masalah yang tercantum dalam penulisan kali ini antara lain:

1.) Tempat lokasi adalah jalan Kalidawir - Desa Ngubalan Kec. Kalidawir Kab.Tulungagung.

2.) Tebal dan jenis bahan perkerasan lentur berdasarkan data sekunder

3.) Metode yang digunakan adalah metode Bina Marga dalam Tata Cara Perencanaan Geometrik Jalan Antar Kota (TPGJAK), Peraturan Perencanaan Geometrik Jalan Raya Tahun 1970, SKBI 2.3.26.1987 dan Analisa Harga Satuan dari Bina Marga.

\section{METODE PENELITIAN}

\section{Landasan Teori}

Klasifikasi jalan di Indonesia menurut Bina Marga dalam Tata Cara Perencanaan Geometrik Jalan Antar Kota ( TPGJAK ) No 038 / T / BM / 1997, disusun pada tabel berikut: 
Tabel 1: Klasifikasi jalan

\begin{tabular}{|c|c|c|c|c|c|c|c|c|c|}
\hline FUNGSI JALAN & \multicolumn{3}{|c|}{ ARTERI } & \multicolumn{3}{|c|}{ KOLEKTOR } & \multicolumn{3}{|c|}{ LOKAL } \\
\hline KELAS JALAN & I & & IIIA & & IIB & & & IIIC & \\
\hline $\begin{array}{l}\text { Muatan Sumbu } \\
\text { Terberat, (ton) }\end{array}$ & $>10$ & & & & & & Tid & ditent & kan \\
\hline TIPE MEDAN & D & B & G & D & B & G & D & B & \\
\hline $\begin{array}{l}\text { Kemiringan } \\
\text { Medan, (\%) }\end{array}$ & $<3$ & $3-25$ & $>25$ & $<3$ & $3-25$ & $>25$ & $<3$ & $3-25$ & $2>$ \\
\hline
\end{tabular}

Panjang maksimum bagian lurus harus dapat ditempuh dalam waktu $\leq 2,5$ menit (sesuai VR), dengan pertimbangan keselamatan pengemudi akibat dari kelelahan. Tikungan

a.) Jari-jari minimum

Supaya kendaraan stabil disaat melewati tikungan, perlu dibuat suatu kemiringan melintang jalan pada tikungan yang disebut superelevasi (e). Pada saat kendaraan melalui daerah superelevasi, akan terjadi gesekan arah melintang jalan antara ban kendaraan dengan permukaan aspal yang menimbulkan gaya gesekan melintang. Perbandingan gaya gesekan melintang dengan gaya normal disebut koefisien gesekan melintang (f).

1. Jarak pandangan lebih kecil dari pada panjang tikungan $(\mathrm{Jh}<\mathrm{Lt})$.

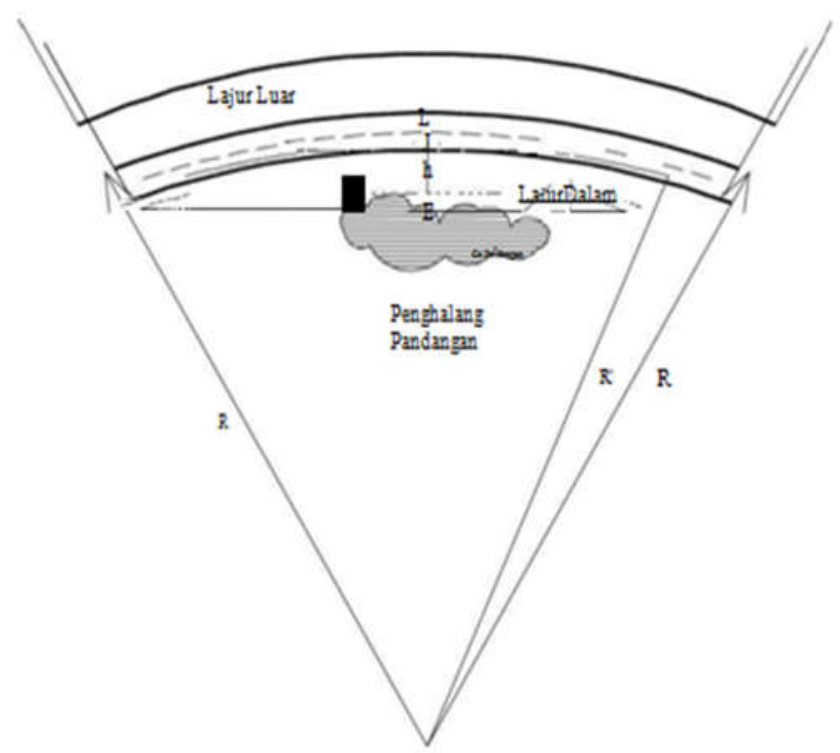

Gambar 1: Jarak pandangan pada lengkung horizontal 
untuk

$\mathrm{Jh}<\mathrm{Lt} \mathrm{Jh} \quad=$ jarak pandang henti $(\mathrm{m})$

$\mathrm{Lt} \quad=$ panjang tikungan $(\mathrm{m})$

$\mathrm{E} \quad=$ daerah kebebasan samping $(\mathrm{m})$

$\mathrm{R} \quad=$ jari-jari lingkaran (m)

Maka: $\mathrm{E}=\mathrm{R}\left(1-\cos 90^{\circ} \mathrm{Jh} / \pi \mathrm{R}\right)$

2. Jarak pandangan lebih besar dari panjang tikungan $(\mathrm{Jh}>\mathrm{Lt})$.

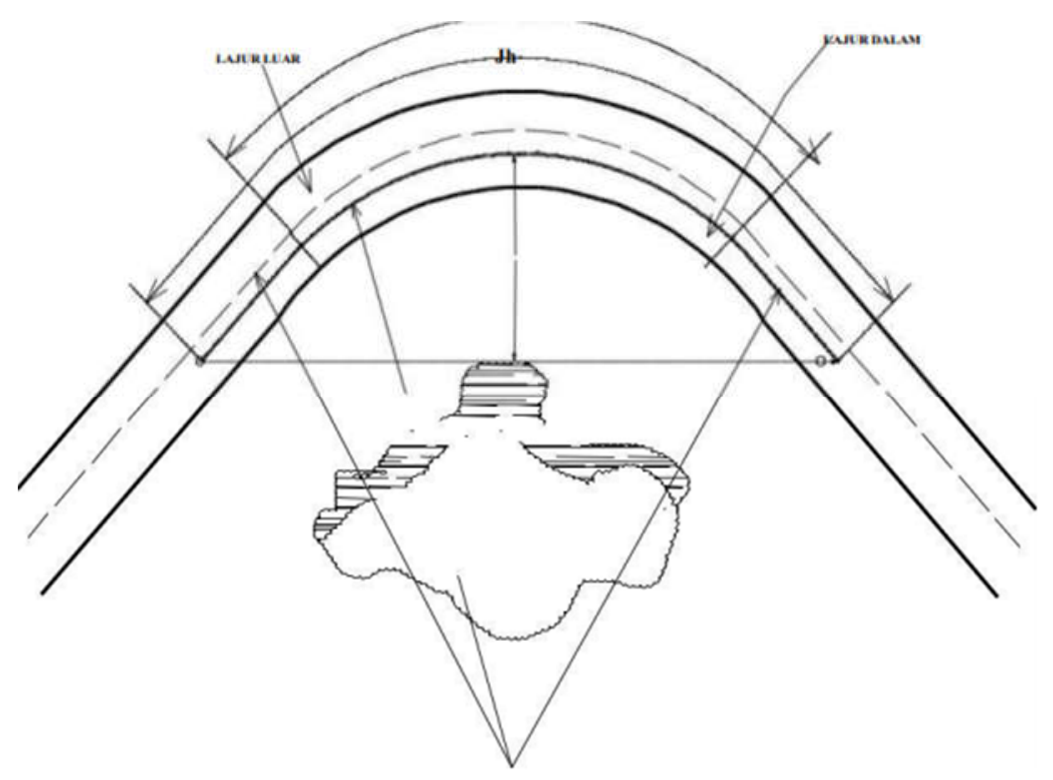

Gambar 2: Jarak pandangan pada lengkung horizontal

Untuk

$\mathrm{Jh}>\mathrm{Lt} \mathrm{Jh}=\mathrm{Lt}+2 . \mathrm{d}$

$\mathrm{d}=1 / 2(\mathrm{Jh}-\mathrm{Lt})$

$\mathrm{m}=\mathrm{R}(1-\cos 90 \mathrm{Jh} / \mathrm{R})+((\mathrm{Jh}-\mathrm{Lt} / 2) \times(\sin 90 \mathrm{Jh} / \mathrm{R})$

\section{Perencanaan Tebal Perkerasan Lentur}

Perencanaan konstruksi lapisan perkerasan lentur, disini untuk jalan baru kita menggunakan Metode Analisa Komponen, yaitu dengan metode analisa komponen SKBI-2.3.26.1987.

\section{Lalu lintas harian rata-rata(LHR).}

Lalu lintas harian rata-rata (LHR) setiap jenis kendaraan ditentukan pada awal umur rencana, yang dihitung untuk dua arah pada jalan tanpa median atau masing- masing arah pada jalan dengan median. 


\section{Tahapan penelitian}

Dalam pengolahan data ini metode yang dilakukan adalah observasi ke lokasi proyek Kalidawir - Desa Ngubalan di Kabupaten Tulungagung Jawa Timur. Selain itu penulis juga mengumpulkan data-data yang diperlukan dalam pengolahan data ini kepada pihak-pihak terkait. Data umum yang terkumpul adalah sebagai berikut:

1. Nama Proyek : Perencanaan Jalan Kalidawir - Desa Ngubalan.

2. Lokasi Proyek : Desa ngubalan kecamatan Kalidawir Kab. Tulungagung.

3. Pemilik Proyek: Pekerjaan Umum Bina Marga

4. Sumber Dana : APBD Tahun Anggaran 2019 Data Teknis

Dalam mendapat data teknis ini penulis mengumpulkan data dari hasil survey. Adapun datadata nya sebagai berikut:

1. Nama Jalan : Jalan Kalidawir - Desa Ngubalan

2. Panjang Jalan: 3200 meter

3. Lebar Jalan : 7 meter Metode Penyusunan

Dalam proses penyusunan study perencanaan ini penulis menggunakan metode penyusunan sebagai berikut:

1. Data hasil survey

2. Pengolahan hasil data survey

3. Design

\section{Metode Pengumpulan Data}

Dalam pengolahan data ini ada beberapa metode yang penting untuk diperhatikan agar perencanaan jalan ini terlaksana dengan baik. Metode yang penulis gunakan dalam penyusunannya adalah sebagai berikut

1. Study Literatur - Literatur

Study literature adalah proses pengumpulan data dari berbagai sumber refrensi terkait dengan jalan

2. Metode Observasi dan Pengumoulan Data Teknis

Dengan mengumpulkan data-data teknis perencanaan jalan dan meninjau langsung ke lokasi proyek.

\section{PEMBAHASAN}

Pada saat perencanaan jalan raya, data-data yang dibutuhkan ialah peta topografi, dengan skala perbandingan 1:25000 sebagai penetapan trace jalannya. Selain itu yang dilakukan adalah menghitung azimuth, sudut tikungan, dan jarak $\mathrm{p} 1$. 
a. Penghitungan Azimut

Diketahui koordinat $\mathrm{A}=(0 ; 0)$

PI $1=(1875: 210)$

PI $2=(2475 ; 645)$

$\mathrm{B} \quad=(2675 ; 1195)$

$\alpha A-1=\operatorname{ArchTg}[\mathrm{X} 1-\mathrm{XA} / \mathrm{Y} 1-\mathrm{YA}]$

$=\operatorname{ArchTg}[(1875-0) /(210-0)]$

$=83036^{\prime} 34,22^{\prime \prime}$

$\alpha 1-2=\operatorname{ArchTg}[\mathrm{X} 2-\mathrm{X} 1 / \mathrm{Y} 2-\mathrm{Y} 1]$

$\alpha A-1=\operatorname{ArchTg}[2475-1875 / 645-210]$

$=54^{0} 3$ '28, $4^{\prime \prime}$

$\alpha 2-\mathrm{B}=\operatorname{ArchTg}[\mathrm{XB}-\mathrm{X} 2 / \mathrm{YB}-\mathrm{Y} 2]$

a 1-2=ArchTg[2675-2475/1195-645]

$=19058^{\prime} 59,18^{\prime \prime}$

\section{b. Penghitungan Sudut PI}

$$
\begin{aligned}
\Delta 1 & =\alpha A-1-\alpha 1-2 \\
& =830366^{\prime} 34,22^{\prime \prime}-5403 ' 28,4 " \\
& =29033^{\prime} 5,82^{\prime \prime} \\
\Delta 2 & =\alpha 4-B-\alpha 3-4 \\
& =5403^{\prime} 28,4^{\prime \prime}-19058^{\prime} 59,18^{\prime \prime} \\
& =3404^{\prime} 29,22^{\prime \prime}
\end{aligned}
$$

\section{KESIMPULAN DAN SARAN}

\section{Kesimpulan}

1. Jenis dari jalan Kalidawir - Desa Ngubalan berupa jalan arteri yang spesifikasinya jalan kelas II, dengan lebar perkerasannya 2 x 3,5 m, dengan kecepatan rencana $40 \mathrm{Km} / \mathrm{Jam}$.

\section{A. Aligment Horizontal}

a. Pada PI1 direncanakan jenis tikungan Spiral-Spiral dengan jari-jari lengkung rencana 200 m, besar sudut PI1 29 33' 5,82".

b. Pada PI 2 direncanakan jenis tikungan Spiral-Circle-Spiral dengan jari - jari lengkung

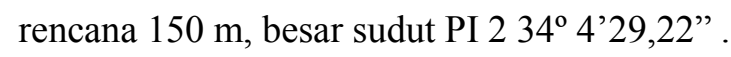

B Aligment Vertikal.

Pada alinemen vertical jalan Kalidawir - Desa Ngubalan terdapat 7 PVI, yaitu : PVI 1 = $7,79 \%$, PVI $2=2,3 \%$, PVI $3=3,36 \%$, PVI $4=9,33 \%$, PVI $5=8 \%$, PVI 6 
$=2 \%$, PVI $7=7,72 \%$ yang untuk mendapatkan keseimbangan antara galian dan timbunan.

2. Perkerasan jalan Kalidawir- Desa Ngubalan menggunakan jenis perkerasan lentur berdasarkan volume LHR yang ada dengan :

a. Jenis-jenis bahan yang dipakai dalam perkerasan ini, adalah :

1) Surface Course : LASTON( CBR 20\% )

2) Base Course : Batu pecah ( CBR 80\% )

3) Sub Base Course : Sirtu ( CBR 50\% )

b. Dengan perhitungan didapatkan dimensi dengan tebal dari masing- masing lapisan:

1) Surface Course : $5 \mathrm{~cm}$

2) Base Course : $20 \mathrm{~cm}$

3) Sub Base Course : $15 \mathrm{~cm}$

3. Perencanaan jalan Kalidawir - Desa Ngubalan dengan panjang $3200 \mathrm{~m}$ memerlukan biaya pembangunan sebesar Rp. 184.795.541.000,00 (Seratus

delapan puluh empat milyar tujuh ratus sembilan puluh lima juta lima ratus empat puluh satu ribu rupiah), dikerjakan selama 1 tahun 1 bulan.

\section{Saran}

1. Perencanaan geometric jalan alangkah baiknya jika data hasil survey langsung di lapangan agar diperoleh perencanaan yang optimal.

2. Perencanaan perkerasan jalan sebaiknya menggunakan data selengkap-lengkapnya, baik data lalu lintas maupun data lainnya. Agar pembangunannya dapat berjalan secara optimal.

3. Proyek ini memperlikan tenaga,biaya yang besar agar dapat menunjang terlaksananya proyek pembangunan jalan ini.

a. Bagi tenaga kerja mendapat asuransi kecelakaan diri dan jaminan keselamatan dan kesehatan kerja mengingat pelaksanaan proyek adalah pekerjaan dengan resiko tinggi.

b. Supaya tidak terjadi degradasi mutu pekerjaan setelah proyek ini selesai dan dapat dipertanggungjawabkan secara teknis maka pengawas harus ada di tempat.

c. Pengendalian mutu seharusnya di laksanakan yang meliputi bahan, administrasi, metode proyek agar mutu pekerjaan sesuai yang telah di tentukan. 


\section{Daftar Pustaka}

[1] Christady, H., 2015, Perancangan Perkerasan Jalan dan Penyelidikan Tanah, Penerbit : Gadjah Mada University Press, Yogyakarta

[2] Departemen Pekerjaan Umum Direktorat Jendral Bina Marga, 1990, Petunjuk Disain Drainase Permukaan Jalan.

[3] Direktorat Jenderal Bina Marga, Departemen Pekerjaan Umum, Jakarta.

[4] Departemen Pekerjaan Umum Direktorat Jendral Bina Marga, 1987, Petunjuk Perencanaan Tebal Perkerasan Lentur Jalan Raya Dengan Metode Analisa Komponen SKBI 2.3.26.1987.

[5] Departemen Pekerjaan Umum, Jakarta Departemen Pekerjaan Umum Direktorat

[6] Jendral Bina Marga, 1997, Tata Cara Perencanaan Geometrik Jalan Antar Kota, Departemen Pekerjaan Umum,

[7] Jakarta Direktorat Jenderal Bina Marga, 1997, Manual Kapasitas Jalan Indonesia, Pusat Penelitian dan Pengembangan Jalan, Bandung

[8] Departemen Pekerjaan Umum Direktorat Jendral Bina Marga, 1970, Peraturan Perencanaan Geometrik Jalan Raya

[9] Dasar - Dasar Perencanaan Geometrik Jalan oleh Silvia Sukirman Penerbit Nova

[10] Direktorat Jenderal Bina Marga, 1997, Manual Kapasitas Jalan Indonesia, Pusat Penelitian dan Pengembangan Jalan, Bandung.

[11] Direktorat Jendral Bina Marga,1970." Peraturan Perencanaan Geometrik Jalan Raya No.13/1970" Penerbit Direktorat Jendral Bina Marga.

[12] Indra wijayanto, 2004, Tugas Akhir Perencanaan Geometrik Jalan Raya, Universitas Sebelas Maret,Surakarta. 